\title{
Growth of magnesium oxide nanoparticles onto graphene oxide nanosheets by sol-gel process
}

\author{
Ju Ran Lee and Hye Young Koo* \\ Soft Innovative Materials Research Center, Institute of Advanced Composite Materials, Korea Institute of Science and Technology, \\ Wanju 565-905, Korea
}

\section{Article Info}

Received 17 August 2013

Accepted 25 September 2013

*Corresponding Author

E-mail: koohy@kist.re.kr

\section{Open Access}

DOI: http://dx.doi.org/

10.5714/CL.2013.14.4.206

This is an Open Access article distributed under the terms of the Creative Commons Attribution Non-Commercial License (http://creativecommons.org/licenses/ by-nc/3.0/) which permits unrestricted non-commercial use, distribution, and reproduction in any medium, provided the original work is properly cited.

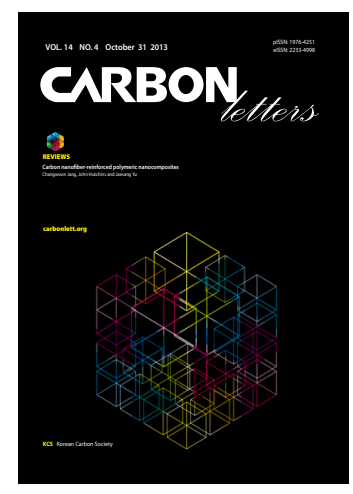

http://carbonlett.org

pISSN: $1976-4251$

elSSN: 2233-4998

Copyright $\odot$ Korean Carbon Society

\begin{abstract}
Nanocomposites comprised of graphene oxide (GO) nanosheets and magnesium oxide $(\mathrm{MgO})$ nanoparticles were synthesized by a sol-gel process. The synthesized samples were studied by X-ray powder diffraction, atomic force microscopy, transmission electron microscopy, and energy-dispersive X-ray analysis. The results show that the $\mathrm{MgO}$ nanoparticles, with an average diameter of $70 \mathrm{~nm}$, are decorated uniformly on the surface of the GOs. By controlling the concentration of the $\mathrm{MgO}$ precursors and reaction cycles, it was possible to control the loading density and the size of the resulting $\mathrm{MgO}$ particles. Because the $\mathrm{MgO}$ particles are robustly anchored on the GO structure, the $\mathrm{MgO} / \mathrm{GOs}$ nanocomposites will have future applications in the fields of adsorption and chemical sensing.
\end{abstract}

Key words: magnesium oxide nanoparticles, magnesium oxide, graphene, graphene oxide, nanocomposites

\section{Introduction}

Magnesium oxide $(\mathrm{MgO})$ nanostructures have drawn special attention because of their important applications in the areas of catalysis, refractory materials, and superconductors [1-3]. Various $\mathrm{MgO}$ structures, such as nanocrystals, nanoparticles, nanocubes, nanowires, and nanosheets have been fabricated successfully [4-6]. For the field of surface chemistry, including such areas as catalysis and adsorption, the fabrication of $\mathrm{MgO}$ nanostructures with high surface area and robustness is a priority.

Graphene nanosheets, a single layer consisting of $\mathrm{sp}^{2}$-bonded carbon atoms, have attracted considerable scientific interest due to their excellent thermal, mechanical, and electronic properties [7-9]. Building of nanocomposites of inorganic nanoparticles onto a graphene sheet would yield the benefit of large surface area [10]. Research into nanocomposites of graphene and inorganic nanoparticles have mostly used chemically exfoliated graphene and its derivatives, such as graphene oxides (GOs) and reduced graphene oxides (rGOs). Because these materials can act as substrates to support adhered inorganic nanoparticles, the resulting nanocomposites can exhibit enhanced properties for adsorption and sensing applications.

In this study, we demonstrate the growth of $\mathrm{MgO}$ nanoparticles on GOs using a solgel process at room temperature. Benefitting from the flat, two-dimensional nanosheet structure of the GOs, the resulting $\mathrm{MgO} / \mathrm{GOs}$ nanocomposites showed $\mathrm{MgOs}$ uniformly grown on the surface of the GOs. It was possible to control the average particle sizes and size distributions by varying the growth conditions of the MgOs. Using X-ray diffraction (XRD) and transmission electron microscopic (TEM) analyses, it was demonstrated that the synthesized MgOs show an amorphous phase with an average particle size of about $70 \mathrm{~nm}$. 


\section{Experimental Section}

\subsection{Materials}

Natural graphite (325 meshes, 99.8\%) was purchased from Alfa Aesar. H2SO4 (97\%) was purchased from Matsunoen Chemicals LTD. KMnO4 and $\mathrm{Mg}\left(\mathrm{NO}_{3}\right)_{2} \cdot 6 \mathrm{H}_{2} \mathrm{O}$ were purchased from Sigma Aldrich. Other chemicals, such as $\mathrm{NaOH}(98.0 \%)$ and $\mathrm{H} 2 \mathrm{O} 2$ (34\%), were obtained from Samchun. Deionized water with a resistance of $18 \mathrm{M} \Omega \mathrm{cm}$ was obtained using a Millipore Simplicity 185 system. All of the chemicals were used without further purification.

\subsection{Preparation of graphite oxide}

The graphene oxide (GO) was prepared using the modified Hummer's method [11]. In a typical procedure, $1 \mathrm{~g}$ of graphite powder was added to $50 \mathrm{~mL}$ of $\mathrm{H}_{2} \mathrm{SO}_{4}$ under stirring, followed by stirring at room temperature for $30 \mathrm{~min}$. To this mixture, $6 \mathrm{~g}$ of $\mathrm{KMnO}_{4}$ was slowly added. The mixture was stirred for $6 \mathrm{~h}$ upon reaching a temperature of $45^{\circ} \mathrm{C}$. Subsequently, $80 \mathrm{~mL}$ of deionized water was slowly added to the mixture with stirring. The color of the mixture turned to yellowish brown. After $30 \mathrm{~min}, 200 \mathrm{~mL}$ of deionized water and $10 \mathrm{~mL}$ of $\mathrm{H}_{2} \mathrm{O}_{2}$ were added to the mixture. After $24 \mathrm{~h}$, the resulting suspension was subjected to dialysis and then filtered through a cellulose acetate membrane with a $0.45 \mu \mathrm{m}$ pore size. After centrifugation and freeze drying, GO powder was obtained.

\subsection{Preparation of $\mathrm{MgO} / \mathrm{GOs}$}

In a typical procedure, an aqueous solution $(1.5 \mathrm{~mL})$ containing $\mathrm{Mg}\left(\mathrm{NO}_{3}\right)_{2} \cdot 6 \mathrm{H}_{2} \mathrm{O}(0.1 \mathrm{mg} / \mathrm{mL})$ was prepared and mixed with an aqueous suspension of the $\mathrm{GO}(0.1 \mathrm{mg} / \mathrm{mL})$. The mixture was vigorously agitated for $4 \mathrm{~h}$ using a shaker. Then, the dispersion was centrifuged at $15000 \mathrm{rpm}$ for 5 to $10 \mathrm{~min}$, the supernatant was removed, and water $(1.4 \mathrm{~mL})$ was added. This washing step was repeated four times. After washing, $\mathrm{NaOH}(0.5 \mathrm{M})$ was added to the dispersion and mixture was allowed to react for 30 min. Again, the resulting dispersion was subjected to centrifugation and washing with water. For the creation of more $\mathrm{MgO}$ nanoparticles on the surface of the GOs, the above procedures were repeated several times.

\subsection{Characterizations}

The distribution of the MgOs on the GOs was analyzed using an atomic force microscope (Dimension 3100, Veeco). XRD patterns of all samples were obtained using an X-ray diffractometer (D/Max 2500, Rigaku) with $\mathrm{Cu} \mathrm{K \alpha}$ radiation to analyze the crystalline structure of the MgOs. A field-emission TEM (FETEM) was used to visualize the microstructure of the MgOs, for the energy dispersive X-ray (EDX) analysis, and for the selected area electron diffraction (SAED) analysis (FE-TEM, JEM 2200FS, Jeol). Particle size analysis was carried out using imaging analysis from TEM and statistical calculation using data from 300 particles.
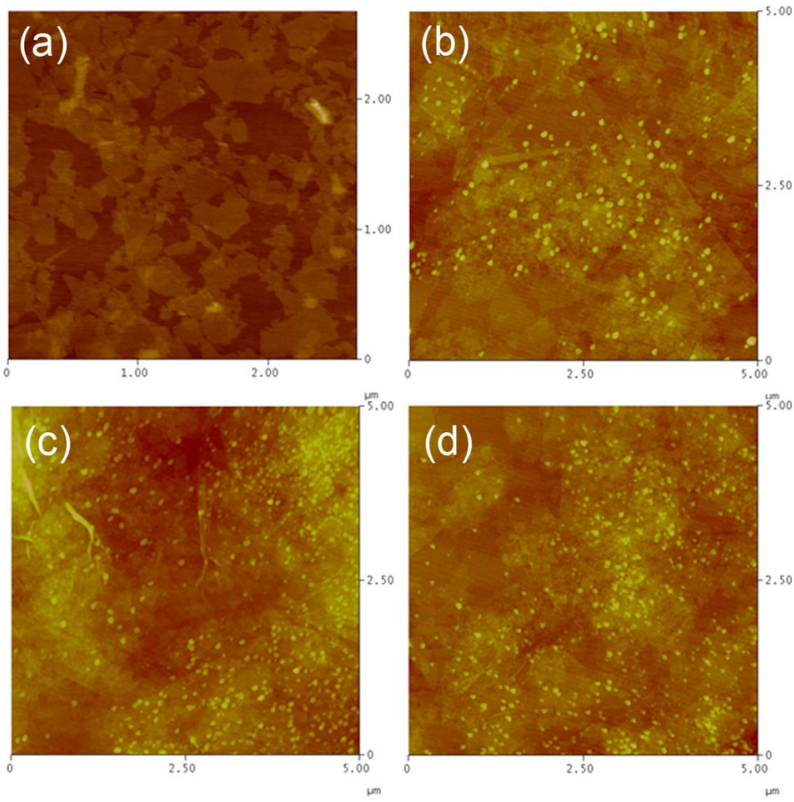

Fig. 1. Atomic force microscopy images of the GOs and the $\mathrm{MgO} / \mathrm{GO}$ : (a) as synthesized GOs, (b) MgO/GOs after 1 reaction cycle (scan size 2.5 $\times 2.5 \mu \mathrm{m}$ ) (c) MgO/GOs after 2 reaction cycles, (d) MgO/GOs after 3 reaction cycles. The scan size for the images (b-d) is $5 \times 5 \mu \mathrm{m}$. GOs: graphene oxides, MgO: magnesium oxide.

\section{Results and Discussion}

\subsection{Atomic force microscopy}

The $\mathrm{MgO}$ nanoparticles were grown on the surface of the GOs using magnesium nitrate $\left(\mathrm{Mg}\left(\mathrm{NO}_{3}\right)_{2} \cdot 6 \mathrm{H}_{2} \mathrm{O}\right)$ as a source material, followed by treatment with $\mathrm{NaOH}$. Fig. 1 shows the atomic force microscopy (AFM) images of the $\mathrm{MgO} / \mathrm{GO}$ nanosheets when the reaction cycles of the $\mathrm{MgO}$ growth are controlled. Fig. 1a shows the GO sheets, revealing lateral dimensions of 10-3000 $\mathrm{nm}$ and heights in the range of 1.1-10 nm; this image was obtained by an analysis of a large number of AFM images. Approximately $80 \%$ of the sheets displayed a height of $1.1 \pm 0.2 \mathrm{~nm}$. The height values are slightly larger than the theoretical height of $0.8 \mathrm{~nm}$; this is thought to be a result of the presence of oxygen-containing functional groups on both faces of the GO sheets [12]. After the reaction cycle of $\mathrm{MgO}$ growth, $\mathrm{MgO}$ nanoparticles of about $60 \mathrm{~nm}$ in size were sparsely distributed on the surface of the GOs (Fig. 1b). When the growth cycle was repeated, the population of $\mathrm{MgO}$ nanoparticles increased with the creation of new nucleation sites (Figs. 1c and d). The size distribution of the $\mathrm{MgO}$ nanoparticles broadened a bit with the repeated reaction cycles because nucleation and growth occurred simultaneously.

\subsection{Particle size analysis}

Fig. 2 shows the particle size distribution for the samples after $\mathrm{MgO}$ growth of up to 3 cycles. The average particle size was about $73 \mathrm{~nm}$, with standard deviation of $24 \mathrm{~nm}$. Because our process did not involve any heat treatment during the $\mathrm{MgO}$ growth, the size distribution of the $\mathrm{MgO}$ nanoparticles did not change significantly for 


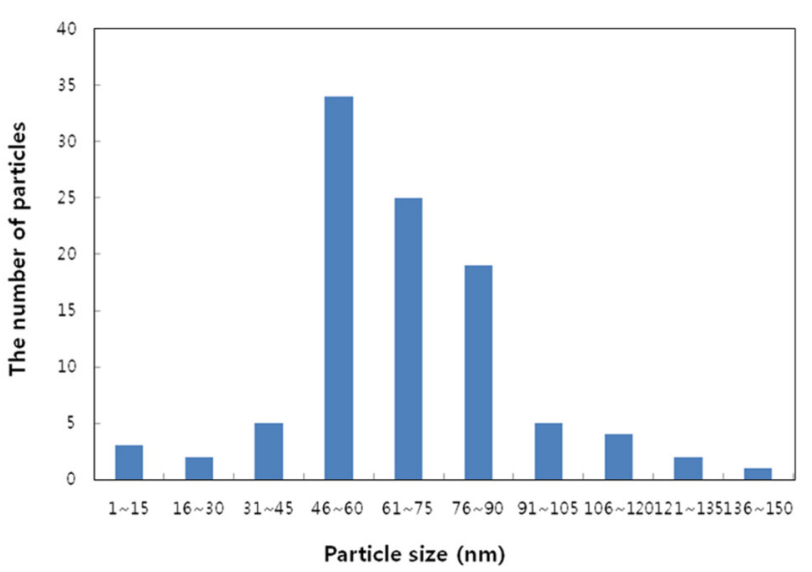

Fig. 2. Particle size distribution of the $\mathrm{MgO} / \mathrm{GO}$ after growth of $\mathrm{MgO}$ for 3 times. MgO: magnesium oxide, GOs: graphene oxides.

up to 3 cycles. If we add a brief heat treatment for the $\mathrm{MgO}$ growth process, the growth speed will be activated and the average particle size for the same growth conditions will increase to $142 \mathrm{~nm}$, with standard deviation of $40 \mathrm{~nm}$.

\subsection{X-ray diffraction}

The XRD spectra from the as-prepared GOs and the $\mathrm{MgO} / \mathrm{GO}$ are presented in Fig. 3. For the GOs, there is a strong and sharp peak located around $11.8^{\circ}$, corresponding to an interlayer distance of $0.76 \mathrm{~nm}$ (d 002). The $\mathrm{MgO} / \mathrm{GOs}$ shows a broad peak centered on $25^{\circ}$, revealing the presence of the amorphous phase of the $\mathrm{MgO}$ nanoparticles, with almost no crystalline structure. Because the growth of $\mathrm{MgO}$ took place at room temperature, most of the grown $\mathrm{MgO}$ nanoparticles are naturally amorphous, without any crystalline phase. When we increase the growth temperature, we can detect the development of the crystalline phase by XRD analysis. The nominal shift of the (002) peak of the GOs is related to the sodium hydroxide treatment for $\mathrm{MgO}$ nanoparticle growth, possibly removing a small amount of oxide groups on the surface of the GOs.

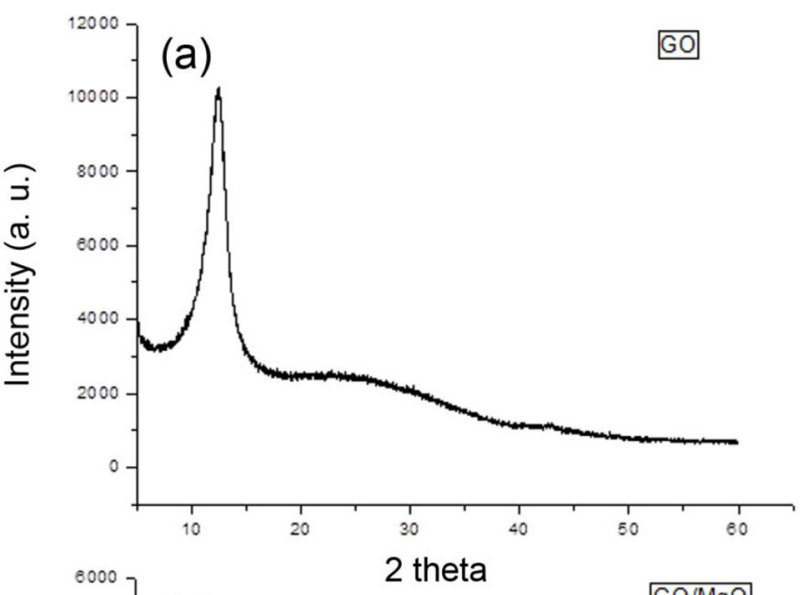

(b)

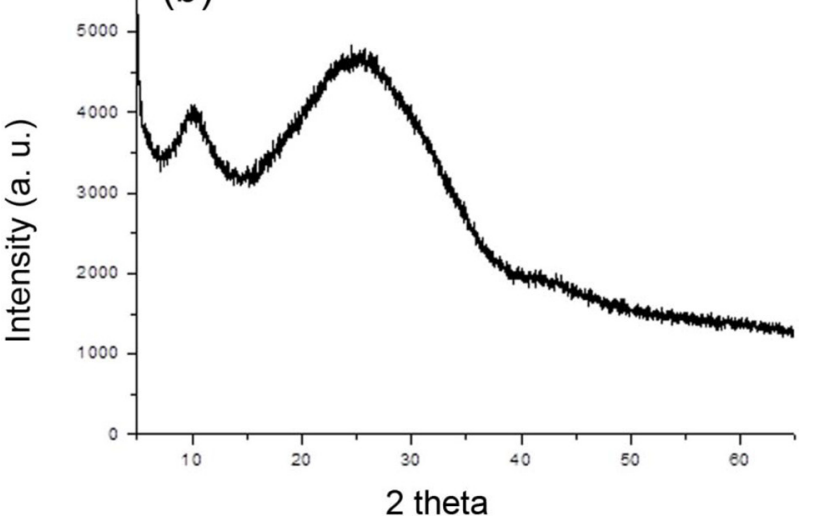

Fig. 3. X-ray diffraction spectra of the samples: (a) GOs, (b) MgO/GOs. GOs: graphene oxides, $\mathrm{MgO}$ : magnesium oxide.

\subsection{Transmission electron microscopy}

With the aim of obtaining a deeper characterization, TEM and EDX spectroscopy were performed on the $\mathrm{MgO} / \mathrm{GOs}$ (Fig. 4). These processes revealed densely distributed $\mathrm{MgO}$ nanopar-
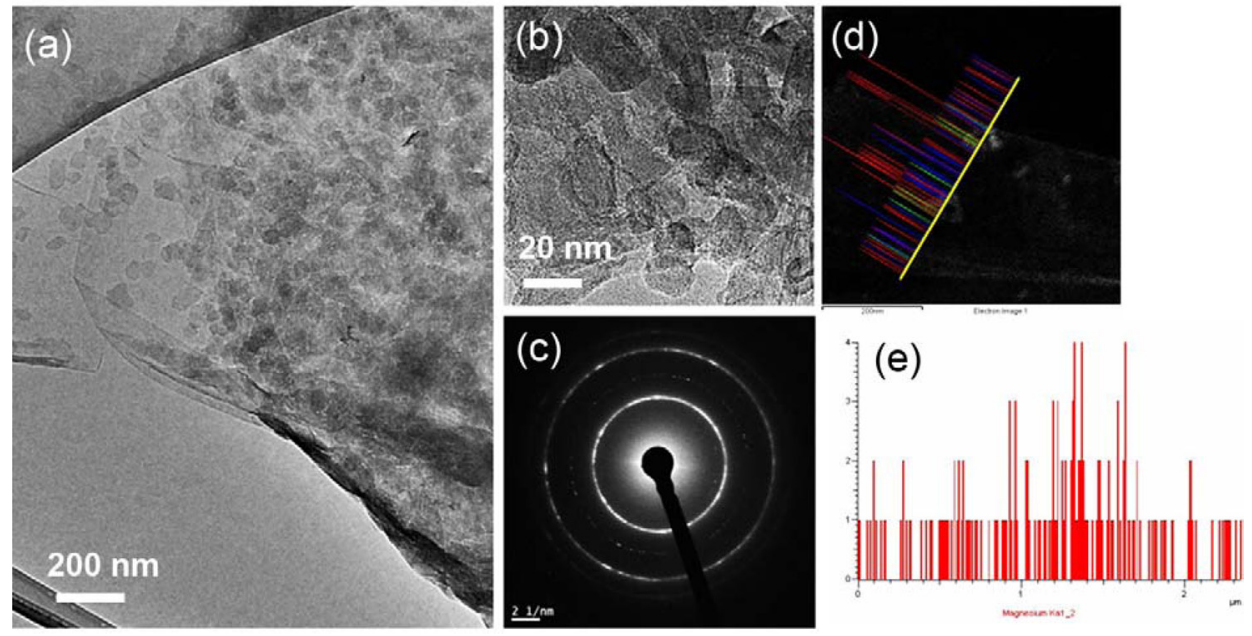

Fig. 4. Transmission electron microscopy (TEM) analyses of the resulting MgO/GOs: (a) typical TEM image of the MgO/GOs, (b) magnified TEM image, (c) selected area electron diffraction from image (b), (d) image for energy dispersive X-ray (EDX) analysis, (e) EDX spectrum showing distribution of magnesium. MgO: magnesium oxide, GOs: graphene oxides. 
ticles on the surface of the GOs (Figs. 4a and b). From the dark field image and the following SAED analysis, we were able to conclude that the morphology of the $\mathrm{MgO}$ nanoparticles is amorphous (Fig. 4c). It seems that the GOs do not have any influence on the crystallinity of the grown $\mathrm{MgOs}$ because of the low growth temperature and relatively defective structure of the GOs. From the EDX analysis, it is clear that the MgO nanoparticles were successfully synthesized on the surface of the GOs (Figs. 4d and e).

\section{Conclusions}

Easy and controllable growth of $\mathrm{MgOs}$ on the surface of GOs with uniform distribution was achieved using a simple sol-gel process. It was possible to control the loading density and particle size distribution through the repetition of the $\mathrm{MgO}$ growth cycles. Without any heat treatment, $\mathrm{MgO}$ nanoparticles with average particle size of around $70 \mathrm{~nm}$ were successfully synthesized on the GOs. The $\mathrm{MgO}$ nanoparticles grown on the GOs show high surface reactivity, and high chemical and thermal stability, which makes $\mathrm{MgO}$ a promising material for applications in fields of sensors and catalysis. The role of $\mathrm{MgO} / \mathrm{GOs}$ as an efficient catalyst for many useful reactions, for example, the methanation of carbon dioxide, will be the subject of our future work.

\section{Acknowledgements}

This work was supported by grants from the Korea Institute of Science and Technology (KIST) Institutional Program (2E24043, 2Z03880), and by a grant from the Converging Research Center Program funded by the Ministry of Science, ICT \& Future Planning Technology (2013K000414).

\section{References}

[1] Li WC, Lu AH, Weidenthaler C, Schüth F. Hard-templating pathway to create mesoporous magnesium oxide. Chem Mater, 16, 5676 (2004). http://dx.doi.org/10.1021/cm048759n
[2] Makhluf S, Dror R, Nitzan Y, Abramovich Y, Jelinek R, Gedanken A. Microwave-assisted synthesis of nanocrystalline $\mathrm{MgO}$ and its use as a bacteriocide. Adv Funct Mater, 15, 1708 (2005). http:// dx.doi.org/10.1002/adfm.200500029.

[3] Choudary BM, Mulukutla RS, Klabunde KJ. Benzylation of aromatic compounds with different crystallites of $\mathrm{MgO}$. J Am Chem Soc, 125, 2020 (2003). http://dx.doi.org/10.1021/ja0211757.

[4] Fang XS, Ye CH, Zhang LD, Zhang JX, Zhao JW, Yan P. Direct observation of the growth process of $\mathrm{MgO}$ nanoflowers by a aimple chemical route. Small, 1, 422 (2005). http://dx.doi.org/10.1002/ smll.200400087.

[5] Stankic S, Müler M, Diwald O, Sterrer M, Knöinger E, Bernardi J. Size-dependent optical properties of $\mathrm{MgO}$ nanocubes. Angew Chem Int Ed, 44, 4917 (2005). http://dx.doi.org/10.1002/ anie.200500663.

[6] Zhu K, Hu J, Küel C, Richards R. Efficient preparation and catalytic activity of $\mathrm{MgO}(111)$ nanosheets. Angew Chem Int Ed, 45, 7277 (2006). http://dx.doi.org/10.1002/anie.200602393.

[7] Novoselov KS, Geim AK, Morozov SV, Jiang D, Zhang Y, Dubonos SV, Grigorieva IV, Firsov AA. Electric field effect in atomically thin carbon films. Science, 306, 666 (2004). http://dx.doi. org/10.1126/science.1102896.

[8] Stankovich S, Dikin DA, Dommett GHB, Kohlhaas KM, Zimney EJ, Stach EA, Piner RD, Nguyen ST, Ruoff RS. Graphenebased composite materials. Nature, 442, 282 (2006). http://dx.doi. org/10.1038/nature04969.

[9] Stoller MD, Park S, Zhu Y, An J, Ruoff RS. Graphene-based ultracapacitors. Nano Lett, 8, 3498 (2008). http://dx.doi.org/10.1021/ nl802558y.

[10] Koo HY, Lee HJ, Go HA, Lee YB, Bae TS, Kim JK, Choi WS. Graphene-based multifunctional iron oxide nanosheets with tunable properties. Chemistry, 17, 1214 (2011). http://dx.doi.org/10.1002/ chem.201002252.

[11] Hummers WS, Jr., Offeman RE. Preparation of graphitic oxide. J Am Chem Soc, 80, 1339 (1958). http://dx.doi.org/10.1021/ ja01539a017.

[12] Schniepp HC, Li JL, McAllister MJ, Sai H, Herrera-Alonso M, Adamson DH, Prud'homme RK, Car R, Saville DA, Aksay IA. Functionalized single graphene sheets derived from splitting graphite oxide. J Phys Chem B, 110, 8535 (2006). http://dx.doi. org/10.1021/jp060936f. 